\title{
Ontological Nominalism and Analytic Philosophy: On the Possibility of Philosophizing whilst Dispensing with Universals
}

\author{
Hossein Dabbagh \\ University of Oxford and Reading
}

\author{
Soroush Dabbagh \\ University of Toronto
}

\begin{abstract}
Most commentators use the term "modern philosophy" for the post-Descartes era-an era of unprecedented growth for the modern sciences and, especially the empirical sciences. Even assuming that the feud between the rationalists and the empiricists during this period yielded no other benefits, it was beneficial enough to turn "experience" into an important pillar of the acquisition of knowledge in the subsequent philosophy. It was this "experience-mindedness" that drove away the Aristotelian "essentialist" perspective and replaced it with "nominalism." By describing the genesis and emergence of the "nominalist-empirical" perspective in analytic philosophy as one of the branches of the human sciences, this article strives to advance the claim that philosophical thinking continues to flourish in the absence of "realist thinking about universals" and that philosophizing does not fundamentally rest on universals.
\end{abstract}

Keywords: ontological nominalism, conceptual nominalism, essentialism

\section{Introduction: Historical Background}

Most historians of science are of the view that the emergence of the modern empirical sciences was the starting point of the Renaissance; sciences initially saw the light of day in the 16th and 17th century Europe and have now - in Marx's words - created a world after their own image. Historically speaking, great scientists such as Galileo, Newton, and Boyle were the founders of this phenomenon in the West. In fact, first the experience-based sciences underwent an upheaval and a transformation, and, then, the sciences that were not experience-based were transformed because of the new questions that had been raised by empirical scientists. If, in their philosophical endeavors, Leibnitz and Kant were striving to take past debates about the concept of time to a higher level and to offer a new, satisfactory explanation of time, it was because of the developments that had taken place in this respect in the field of physics under Newton's influence. For example, the linear view of time, which was discussed in Kantian philosophy, was very much inspired by Newtonian physics. The modern sciences presented philosophers with problems of this kind and made them reflect and theorize anew. ${ }^{1}$ The modern empirical sciences also placed new questions before the giants of the human sciences, such as

Hossein Dabbagh, research fellow, Center for Socio-Legal Studies, Law Faculty, University of Oxford and Department of Philosophy, University of Reading, England; main research field: Moral Philosophy, Moral Psychology, and Epistemology. Email: hosein.dabbagh@gmail.com.

Soroush Dabbagh, postdoctoral fellow, Historical Studies Department, University of Toronto, Canada; main research field: Moral Philosophy and Philosophy of Language. Email: soroush.dabbagh@gmail.com.

In as much as this article is an examination of analytic philosophy, it does not take a stance, one way or the other, on continental philosophies. This subject-i.e., the examination of the role of nominalism in the emergence of continental philosophies - is the basis of a separate article. 
Descartes, Locke, and Hume. They were put in a position where they constantly had to grapple with these issues and to do their utmost to construct their philosophical edifice and knowledge system in a way that addressed the emerging problems ${ }^{2}$ that made them turn away from metaphysics (in the traditional sense of the word) and drove them to tackle the emerging philosophical problems with an eye on the material world rather than the metaphysical world. It is self-evident that this striking change in perspective is one of the important consequences of the emergence of the modern sciences in the West.

By way of another example of the impact on philosophy of other fields of learning, we can look at the revolution that occurred in the realm of philosophy in the late 19th century which led to the emergence of analytic philosophy. Historians and commentators have so far put forward a variety of hypotheses about the genesis and emergence of analytic philosophy. For example, Anthony Kenny is of the view that analytic philosophy can be said to have begun in 1884, when the theory of the context principle was propounded in The Foundations of Arithmetic by Frege. ${ }^{3}$ At the same time, when it is a question of tracing the roots of analytic philosophy, the Vienna Circle, too, receives a fair share of attention. The rise and fall of the Vienna Circle can be dated to the interval between the First and the Second World Wars. Although the contentions of the members of the Vienna Circle cannot be said to have mostly fallen under the banner of analytic philosophy, most of the works - over the course of the history of analytic philosophy - that have been devoted to criticism of metaphysics and metaphysical thinking have been linked to the Vienna Circle.

Hans Glock traces the Vienna Circle's anti-metaphysical approach to three of their important teachings: first, the means that Frege and Russell's new logic furnishs for philosophical analysis; secondly, the teaching in Wittgenstein's Tractatus that tautology carries its own necessity, in other words, there is basically no non-tautological necessity; and, finally, the verificationist theory of meaning, which sparks off many feuds and debates. ${ }^{4}$ It can, moreover, be assumed that the criticism and rejection of metaphysics and metaphysical thinking that is on the Vienna Circle's agenda is intertwined with their criticism of realism about universals. We must bear in mind Putnam's view that analytic philosophers only tend to promote an anti-metaphysics approach during the early days after the birth of analytic philosophy (relating to the years of the Vienna Circle). This approach gradually takes on a different form with the decline of the Vienna Circle.

It seems that not all the early proponents of analytic philosophy are necessarily concerned with criticizing metaphysics. For example, in his article entitled "The Thought," in order to defend the objectivity of meaning, Frege assumes a realm in which thoughts reside. Assuming such a realm is a kind of metaphysical thinking. Then again, at least for a time, Frege subscribes to the redundancy theory of truth, which, among theories of truth, clearly has an anti-metaphysical tint. It might be fair to say that Frege's relationship with metaphysics, over the years of his philosophical work, is ambiguous.

We can also find an alternative anti-metaphysical approach in Quine's works. In his writings (in 1969), he defends a kind of "naturalized epistemology," in the sense that discussing language and meaning alone will not solve our problems; philosophy and epistemology have a manifest link with the natural sciences and epistemology is basically a part of psychology. So, we can consider it part of the natural sciences. Moreover, in Quine's knowledge system, inquiring about phenomenon and where they fit in the world (in the metaphysical sense) is of considerable importance philosophically. ${ }^{5}$

Moreover, in What is Analytic Philosophy, Hans Glock tries to discuss at length the non-Anglo-America roots of (Austrian-German) analytic philosophy. He is of the view that analytic philosophy is neither wholly Anglo-American, nor wholly non-Anglo-American. Both philosophers of Austrian-German origin, such as 
Carnap, Frege, Wittgenstein, Schlick, Popper, etc., and philosophers of Anglo-American origin, such as Russell, Moore, Quine, McDowell, etc., play an important part in its emergence. It is true that most analytic philosophers are not fond of continental philosophy and, specifically, the idea of synthetic a priori propositions and, on this basis, opts for a different path from continental philosophy. But, in as much as they deem philosophy to be a second order discipline, they are in step with continental philosophers such as Kant.

As we said, the founders of this philosophical school of thought-who mainly hail from Cambridge - consist of Moore, Russell, Frege, and Wittgenstein. They are of the view that the problem that philosophers have to grapple with is that lack of clarity and precision in the use of language, which is the most important tool for communicating meaning and exchanging philosophical teachings. For this group of philosophers, the language of the conventional sciences (i.e., the language that scientists in various empirical fields such as biology, physics, chemistry, etc., use to formulate their data) is an exemplary tool for communicating knowledge, because it is free of ambiguity and can convey meaning with the utmost precision. In the same way, they strive to present a philosophical language that is clear and unequivocal and could be used to express unambiguous philosophical propositions. The distinction Russell draws between propositions' logical form and grammatical form, Wittgenstein's picture theory of meaning and his effort to purge language of ambiguity, and the Vienna Circle's verifiability principle all have to be understood in this light. ${ }^{6}$

Now, the question arises: Why do scholars adopt the scientific-empirical view of being? Epistemologically speaking, what are the necessary elements and presuppositions that underpin this view of being? As Kant would put it, what are the necessary conditions for such a view to become possible? What fundamental assumptions may have to change in order for the scientific view of being to become a possibility?

\section{Essentialisms vs. Nominalisms}

The above questions demand a variety of sociological, anthropological, historical, psychological, etc., studies. In other words, here, we are faced with a multi-dimensional problem and a single-factor analysis does not seem appropriate. It calls for collective efforts by scholars in a range of human sciences who can examine the problem from numerous dimensions. This article looks at the philosophical and epistemological aspect, in as much as it is one important and influential factor.

In response to the above-mentioned questions, we can say, with utmost brevity, that the crux of the non-scientific and non-empirical view of being and nature is essentialism, and that the crux of the scientific and empirical view of the world is nominalism and the rejection of essentialism. Hence, it may be useful to begin by noting a few points about these two viewpoints.

Essentialism, as a philosophical viewpoint, can be discussed from two perspectives. One perspective relates to conceptual essentialism and, the other, to ontological essentialism. Ontological essentialism means that we can assume that universals exist in the world. But conceptual essentialism means that words such as "water" or "tree," which are used in everyday language, denote numerous individual instances in the external word and refer to them. What we are concerned with in this article is ontological essentialism, which is originally advanced by thinkers such as Plato and Aristotle, albeit with different readings. This theory claims that every entity that exists in this world is made up of unchanging attributes and inviolable properties, which can be grasped and enumerated. For example, when a language-user uses the term "human being" and, in so doing, intends to convey a meaning, according to the classic essentialist viewpoint, he is referring to a characteristic or characteristics that all human beings share. It is by bearing in mind these inviolable properties 
and attributes that the language-user's words convey a meaning. This way of specifying a meaning can be called definition using genus and species (in the sense that, according to the Aristotelian logic, the human being is defined as a speaking animal, whereby animal is the genus and speaking is its species or distinguishing feature). This point holds true both for natural concepts, such as tree, mountain, forest, water, etc., and for concepts that are social constructs, such as state, war, and democracy.

An essentialist philosopher, in the context of ontology, believes that all entities have an essence with definable components. In the context of epistemology, the essentialist philosopher believes that this essence and inviolable properties are knowable. In other words, essentialist philosophers are of the view that speaking of an entity's essence and properties does not hinge on experience. In fact, referring to the external world and experience is not involved in discovering the properties and characteristics of an entity's essence. Instead, an entity's essence can be defined in a priori way and prior to any experience. Its properties can be grasped (from the ontological perspective) and it can become known (from the epistemological perspective).

Bearing in mind the above-mentioned explanation, it must also be recalled that, in the second half of the 20th century, thinkers like Kripke seek to revive essentialism. In Naming and Necessity, Kripke speaks of a kind of essentialism, which is, in the first instance and essentially, conceptual. In other words, adhering to conceptual essentialism, as expounded by Kripke, does not entail an acceptance of ontological essentialism. Moreover, at present, there are analytic philosophers, such as Armstrong, who subscribe to the existence of universals in the ontological sense. ${ }^{7}$

Having reviewed the characteristics of the essentialist viewpoint, let us turn to the nominalist viewpoint. ${ }^{8}$ There are at least two kinds of nominalism: One is directed at rejecting abstract entities and the other is directed at rejecting universals. The point worth highlighting here is that both these kinds of nominalism are considered to be anti-realist viewpoints, in the sense that nominalism is considered to be the opposite of the Platonic realist perspective.

In much the same way as the essentialist philosophical viewpoint, the nominalist viewpoint has two branches: conceptual nominalism and ontological nominalism. Ontological nominalism conveys the sense that universals do not exist in the external world. In conceptual nominalism, the idea is that the words that we use in language are no more than names. In this way, conceptual nominalism stands opposed to conceptual essentialism, which subscribes to the view that the words that we use in language are universal concepts that denote their instances in the external world.

The nominalism that we are concerned with in this article is ontological nominalism. This viewpoint uses different ontological and epistemological tenets and underpinnings from the essentialist viewpoint. An ontological nominalist like Hume or Berkley ${ }^{9}$ does not subscribe to the idea of essence in the Aristotelian sense and to an essentialist view of being, which is described above: an essence, which has properties that can be defined and determined prior to experience (ontological), and which can, on principle, be the object of our knowledge (epistemological). In fact, instead of assuming an inviolable-Aristotelian essence as an ontological presupposition, nominalism speaks of violable, empirical attributes.

In effect, if, in the context of ontology, someone speaks of an essence that can be defined a priori and prior to experience, he has no need to refer to the external world and to experience in order learn about the assumed essence; he can speak about the essence's properties and know about it prior to any experience. But, if, instead of essence, someone takes as his ontological presupposition a list of the properties and attributes of a concept which in principle can increase or decrease, he has in fact acknowledged that the list is tentative and that 
enumerating the properties and attributes must be left to an open-ended empirical process. In other words, assuming such a list of attributes amounts to adopting a minimalist ontological assumption, which forms the basis of efforts towards the acquisition of knowledge. A nominalist takes the view that the concept "tree," for example, can comprise a variety of attributes, which can be discovered gradually in the course of studies that demand recourse to the external world and experience.

Alternatively, a conceptual nominalist like Wittgenstein, in his Philosophical Investigations, explains the concept of "game" by speaking of the idea of family resemblances. He is of the view that different games reference different characteristics in the external world. This means that, in conceptual terms, "game" has no essence. In fact, there are resemblances between different games which are like the resemblances among the members of a family (resemblances between the eyes, eyelashes, eyebrows, or mouth of a mother and father with those of their children) which can only be discovered by referring to the external world. For example, consider games such as football, snooker, chess, basketball, volleyball, tennis, and boxing. A characteristic such as a ball can be seen in football, volleyball, basketball, and tennis, whereas no ball is involved in boxing and chess. Or, take the presence of a net as a characteristic. Tennis and volleyball require a net, whereas no net is involved in snooker, cricket, and American football. As we can see, there is no attribute that is presented in all the above-mentioned games. Be that as it may, our linguistic intuitions decree that using the word "game" for all the mentioned instances and conveying a meaning in so doing is entirely acceptable. In other words, no language-user would harbor any doubt in applying the word "game" to badminton, snooker, etc.

Someone may say, by way of an objection, that winning and losing are a common characteristic of the above-mentioned games. But imagine the case of a little boy who is swaying back and forth on a playground swing. Our linguistic intuitions view this phenomenon as a kind of game. This is circumstances in which no ball is involved in this game; nor is there any winning or losing. So, if we want to speak of a common characteristic that exists in all the above-mentioned games, it would appear that there is none. Hence, for Wittgenstein, in his capacity as a conceptual nominalist, seeing the similarities plays an irreplaceable role in explaining the genesis of the meaning of concepts. ${ }^{10}$ In fact, since the genesis of the meaning of concepts cannot be formulated in an a priori, non-empirical way, it is imperative to seek the aid of experience by looking at similarities and dissimilarities in order to arrive at the meaning of terms such as "game."

In short, we can say that ontological nominalism entails a rejection of the assumption that objects and phenomena have essences. Instead, it adopts an empirical-posteriori approach to discover, bit by bit, the different characteristics of a phenomenon, without ever claiming full knowledge of it (epistemologically-speaking).

In the West, with the emergence of the Renaissance and the Scientific Revolution, the nominalist-empirical approach replaces the essentialist-non-empirical approach. ${ }^{12}$ This non-empirical presupposition becomes the central pillar of the scientific and empiricist view of the world. In a possible world - in the Kantian sense of the term-in which the essentialist-non-empirical viewpoint is scholars' metaphysical presupposition, empirical science, in the form that it emerges in the West, cannot come into being. In the West, first, scholars adopt nominalist-empirical presuppositions and, then, they set about uncovering being and producing empirical science.

The essentialist-non-empirical way of thinking considers everything to be determined in advance. So, in this way of viewing being, the assumption that every phenomenon has an essence and a nature has the upper hand. In order to know a phenomenon, it is enough for us to grasp its essence and nature. But in the 
nominalist-empirical way of thinking, there is no nature and essence. In the realm of knowledge, the constant humble assumption is that, in our investigations, we only acquire some knowledge about a phenomenon; not full knowledge. And this process of acquiring knowledge is always open-ended. As Muslim philosophers would put it, the action itself is the action's end and purpose, and there is no final limit. Essentialist-non-empirical presuppositions close the way to the official recognition of the external world and experience of the external world. That philosophy's doors and window are closed to the empirical method, because everything is clear, definite, and graspable prior to experience. In such a possible world, empirical science will not come into being.

\section{Concluding Remarks}

We can conclude on the basis of what has been said above that, historically speaking, ontological nominalism paves the way for and is a precondition for the genesis of analytic philosophy in the west. The close relationship that philosophy acquires with a range of sciences, including the empirical human sciences and the non-empirical human sciences, is beneficial - if for no other reason-because it generates new problems for philosophy. In fact, a huge part of that development could be attributed to the adoption of the empirical-non-essentialist viewpoint and presuppositions. The notions that "human thought is fundamentally based on the existence of universals," that "without universals, thought cannot, in any way, be orderly and cohesive," and that "with the rejection of universals in the West, its formerly flourishing philosophy has gone into decline" do not seem correct on the basis of what has been said in this article, since, a glance at the emergence of analytic philosophy and its pioneers, i.e., classical empiricists such as Locke, Berkley, Hume etc., allows us to conclude that a new branch has emerged in Western philosophy that suggests it is still flourishing. ${ }^{13}$ It can also be claimed that at least some of the philosophers within this branch of philosophy have advanced their philosophical project by setting aside universals. This leads us to believe that the claim that thought fundamentally hinges on the assumption of universals is not justified.

Finally, in order to indigenize the branch of Western philosophy that is known as analytic philosophy, it is important to entrench, teach, and explain the notion that this branch of philosophy has a nominalist-empirical backdrop. This idea will help foster a better understanding of the tenets and requisites of the emergence of analytic philosophy.

Notes

1. For more on Newton's services to philosophy, read: Arthur Burtt, The Metaphysical Foundations of the Modern Science, Chapter 7.

2. For a more thorough understanding of the claim that Locke's theory about knowing is, in a way, influenced by the transformation in science, see: Locke, J. (1689), An Essay Concerning Human Understanding, collated and annotated by A. C. Fraser (Book 4, 452-3).

3. Glock, H. (2008), What is Analytic Philosophy? 123.

4. Ibid., 117-8.

5. Quine, W. V. (1969), "Epistemology Naturalized," in his Ontological Relativity and Other Essays. 75.

6. This article is not devoted to a detailed explanation of the claims made by analytic philosophers. In order to understand analytic philosophy's claim about modern science (whether empirical or non-empirical) and its relationship to philosophy, see: Donald Gillies, Philosophy of Science in the 20th Century; Carnap R. (1934) Logische Syntax der Sprache (The Logical Syntax of Language), trans. A. Smeaton and Dummett, M. (1993) Origins of Analytic Philosophy.

7. Thinkers who subscribe to ontological essentialism do not seem to be in the majority among analytic philosophers. For more on conceptual essentialism, see Saul Kripke, Naming and Necessity. See also: Armstrong, D. M., What is a Law of Nature. 77-85. 
8. See: $<$ http://plato.stanford.edu/entries/nominalism-metaphysics/>.

This article is not aimed at a detailed, historical treatment of the emergence of nominalism. But, in order to clarify the bone of contention, it may be useful to explain that the Platonic viewpoint defends a kind of ontological framework for objects (universals). These objects, such as kinds, relations, and possible states are things that can in no way be reduced to other objects. Conversely, the nominalist viewpoint rejects the existence of these universals and seeks to show that that the debate about universals can be reduced to a debate about particulars. At various points in time, a range of issues have inflamed the dispute between nominalists and Platonists. For example, in the Middle Ages, nominalists like Abelard and Ockham are of the firm view that anything that exists is merely particular. They argue that speaking about universals is like speaking about linguistic expressions. This is why they try to entrench meaning-related views in reference to universals. In the 18th and 19th centuries, on the one hand, Locke is of the view that representations have particular contents and he describes universals as abstract ideas. On the other hand, Berkley and Hume attack him, saying that the content of ideas is established in advance and that they are derived from particulars. Then, it is Kant's turn. By highlighting the role of experience in the genesis of knowledge, Kant breathe new life into nominalism. In contemporary times (20th century), especially in analytic philosophy, ontological debates focuse on the problem of universals. Someone like Moore, in his treatment of logic and the subject-predicate analysis of propositions, turns to a nominalist viewpoint and rejects references to non-linguistic universals. It is also worth mentioning late Wittgenstein's endeavors in this respect. By presenting the concept of "games," he seriously challenges the Platonic viewpoint. It should also be said that, in recent years, in the debate about the philosophy of arithmetic, the views of Platonists comes to the fore again and receives some responses. For example, Quine, whose works reveal faint traces of nominalism, writes in his book Word \& Object in 1960 that there is only one kind of abstract entity which can be verified; viz., mathematical entities. Another defender of Platonism in the philosophy of physics is James Brown. In his book The Laboratory of the Mind, he has set out this idea very well.

9. For example, in order to substantiate his rejection of material quiddity, Berkley uses the theory of nominalism. See: Berkley, G. (1710), A Treatise Concerning the Principles of Human Knowledge, in C. Turbayne (ed.), Principles, Dialogues, and Correspondence.

10. Fogeline, R. (1996), "Wittgenstein's Critique of Philosophy,” in Sluga, H. and Stern, D. (eds.), The Cambridge Companion to Wittgenstein. 34-58. Luntley, M. (2003), Wittgenstein: Meaning and Judgment, Chapters 3, 4.

11. It may be said that the critique of essentialism by someone like Wittgenstein is first and foremost directed at conceptual essentialism. At the same time, accepting conceptual nominalism will lead to a critique of ontological essentialism.

12. See: Ernest Cassirer, The Philosophy of the Enlightenment. See also: John Dunn, The Enlightenment.

13. Muslim philosophers, e.g., Suhrawardī and Mulla Sadrā who were also Platonists believed in this sort of essentialistic-universalistic philosophy.

\section{Works Cited}

Abelard, P. "Logic for Beginners.” Ed. R. McKeon. Selections from Medieval Philosophers. New York: Scribners, 1959. 202-58.

Armstrong, D. M. What is a Law of Nature. Cambridge: Press Syndicate of the University of Cambridge, 1991.

Berkeley, G. "A Treatise Concerning the Principles of Human Knowledge." Ed. C. Turbayne. Principles, Dialogues, And Correspondence. New York: Bobbs-Merrill, 1710; 1965.

Brown, J. R. The Laboratory of the Mind, London: Routledge, 1991.

Burtt, A. The Metaphysical Foundations of the Modern Science. Mineola: Dover Publications Inc., 2003.

Carnap, R. Logische Syntax der Sprache (The Logical Syntax of Language). Trans. A. Smeaton. Patterson: Littlefield \& Adams, 1934.

Cassirer, E. The Philosophy of the Enlightenment. Princeton: Princeton University Press, 2009.

Dummett, M. Origins of Analytic Philosophy. Cambridge: Harvard University Press, 1993.

Dunn, J. The Enlightenment. San Diego: Lucent Books, 1998.

Fogeline, R. "Wiittgenstein's Critique of Philosophy." Eds. Sluga, H. and Stern D. The Cambridge Companion to Wittgenstein. Cambridge: Cambridge University Press, 1996.

Gillies, D. Philosophy of Science in the 20th Century. Oxford \& Cambridge: Blackwell Publishers, 1993.

Glock, H. What is Analytic philosophy. Cambridge: Cambridge University Press, 2008.

Hobbes, T. Leviathan. Ed. M. Oakeshott and R. Peters, New York: Collier. $1651 ; 1962$. $<\mathrm{http} / /$ plato.stanford.edu/entries/nominalism-metaphysics/>.

Locke, J. An Essay Concerning Human Understanding. Collated and annotated by A. C. Fraser. Oxford: Oxford, 1689.

Luntley, M. Wittgenstein: Meaning and Judgment. Oxford: Blackwell, 2003.

Quine, W. V. Ontological Relativity and Other Essays. New York: Columbia University, 1969.

Wittgenstein, L. Philosophical Investigations. Trans. G. E. M. Anscombe. London: Macmillan, 1953. 